\title{
International Research Journal of Public Health (IRJPH)
}

\section{Community Based Management of Malaria: exploring the capacity/ performance of Community Based Agents and their motivation in Tamale, northern region of Ghana 2013}

\author{
Mukaila Zankawah Mumuni1*, Korkortiakor Baba Sadique Zankawah2, Mohammed A. \\ Soghaier3 Patrick Adam1 Iddrisu Jamaldeen Zankawah4
}

1Ghana Health Service, Metropolitan Health Directorate, Tamale; 2National Health Insurance Authority, Claims Processing Center-Tamale, Ghana; 3 Directorate of Epidemiology \& Zoonotic Diseases, Sudan Federal Ministry of Health, Khartoum, Sudan; 4Ghana Health Service, Tamale West Hospital, Tamale

\section{ABSTRACT}

Background: The use of antimalarial drugs and the prevention of man and vector contact remain the major control and prevention strategy of malaria until the availability of effective and safe vaccine. In Africa, one of the major strategies to malaria control and prevention is the home based malaria strategy through which trained community drug distributors identify and provide antimalarial drugs to children under five years with fever. This research aims at exploring the capacity, performance, and motivation of CBAs in Tamale Metropolis, Northern region, Ghana. Methodology: A Survey, in-depth interviews and short ethnographic techniques were conducted among 104 CBAs who were trained and given logistical support to assess and treat children less than five years with malaria presumptively at home. Participants were selected randomly and represented urban, peri-urban and rural settings. Results: $96.2 \%$ of respondents identified malaria by presence of fever while $92.3 \%$ used fever as a cardinal sign. More than $82 \%$ of participants provided early treatment in all the three location. $64.4 \%$ of participants administered the correct number of days while $32.7 \%$ administered daily doses correctly, only $24 \%$ of CBAs knew that the Antimalarial medications they use have some side effects. $77.9 \%$ knew when to repeat drug dose when child vomit or when parent forget to give the dose. Most of the participant had registers and were

*Correspondence to Author:

Mukaila Zankawah Mumuni. Ghana Health Service, Metropolitan Health Directorate, Tamale. E-mail: mzankawah @yahoo.co.uk Tel: +233200545855

How to cite this article:

Mukaila Zankawah Mumuni et al., Community Based Management of Malaria: exploring the capacity/ performance of Community Based Agents and their motivation in Tamale, northern region of Ghana 2013. International Research Journal of Public Health, 2017; 1:2.

\section{eSciencePublisher}

eSciPub LLC, Houston, TX USA. Website: http://escipub.com/ 
reporting monthly, however, only $26.2 \%$ are somewhat motivated by some of the existing of the motivational packages. Conclusion: The overall performance and skills demonstrated by the CBAs are encouraging in all the three settings but documentation and reporting remains a challenge. Community based initiatives should be strengthened and promoted to provide homemade solutions in saving lives especially in resources limited settings. If community interventions such as community drug distribution of antimalarial drugs are needed to improving access to malaria prevention, much attention to what motivates individuals to strengthen their spirit of volunteerism is required.

Keywords: Malaria, Home based management, child mortality, Community Based Agents

\section{Introduction}

Malaria remains one of the major public health challenges in the world and it continues to burden the overstretched health services of the fragile health sector of many developing countries. It is estimated that 214 million cases were reported in 2015 with Sub Saharan Africa accounting for $88 \%$ of all cases $90 \%$ of all deaths [1]. In Ghana, malaria is the leading cause of morbidity and mortality and its transmission occurs throughout the year [2, 3,4, 5]. The use of antimalarial drugs and the prevention of man and vector contact remain the major control and prevention strategy until the availability of effective and safe vaccine. Globally, one of the major priority strategies to malaria control and prevention has been prompt and easy access to first line antimalarial treatment. Home base management of malaria is one key intervention to ensure prompt and easy access recommended by WHO to Africa where most children die before getting to health facilities due to factors such as poor access to health facilities, poor quality of health service, poverty and behavior of health worker [6].

Home Based Management of Malaria (HMM) involves the presumptive treatment of febrile children at or near home with antimalarial drugs distributed by trained members of the community [7]. Some of the services provided by Community Based Agents (CBAs) also called Community Drug Distributors (CDDs) include early identification of fibril conditions in children, prompt initiation of presumptive treatment with antimalarial drugs, conducting follow up on children who reported to them, treatment of new minor ailments, identification of danger signs, referral of children below 6 months and those with danger signs to the next level for treatment and educating care givers on malaria control and prevention strategies [8].

The patronage of community drug distributors has been encouraging and their performance has improved malaria case management at the community level and contributed to lessening the severity and mortality due to malaria $[9,10]$. CBAs are voluntary workers and to sustain their spirit of volunteerism good incentive of motivation packages are essential. This study seeks to determine the current capacity and practice of CBAs in the management of malaria in the three geographical distinct and the factors that motivate them to continue to work as volunteers in Tamale Metropolis.

Ethical approval was obtained from the Committee on Human Research, Publications and Ethics (CHRPE) of Kwame Nkrumah University of Science and Technology (KNUST) School of Medical Sciences; informed consent was obtained from all selected study participants.

\section{Materials and Methods}

\section{Study design:}

Survey, in-depth interviews and short ethnographic techniques were conducted among Community Based Agents

\section{Study Area:}

The study was carried out in Tamale Metropolis of the Northern Region of Ghana. The Metropolis has an estimated land size of $646.90180 \mathrm{sq} \mathrm{km}$ and population of 233,252 according to the 2010 Population and Housing Census. The Metropolis is divided into 4 sub district according to the health system's structure for easy administration. It has 197 communities and each community has 
Table 1: characteristics of respondents

\begin{tabular}{|l|c|c|}
\hline \multirow{2}{*}{ Socio Demographic Variable } & \multicolumn{2}{c|}{ CBA } \\
\cline { 2 - 3 } Age & $\mathrm{N}$ & $\mathbf{N}$ \\
\hline$>29$ & 32 & (\%) \\
\hline $30-39$ & 42 & 30.8 \\
\hline $40-49$ & 19 & 40.4 \\
\hline $50-70$ & 11 & 18.3 \\
\hline Sex & & 10.6 \\
\hline Male & 76 & 73.1 \\
\hline Female & 28 & 26.9 \\
\hline Marital status & & 98 \\
\hline Married & 102 & 1.9 \\
\hline Not married & 2 & 17.3 \\
\hline Level of education & & 31.7 \\
\hline Tertiary & 18 & 14.4 \\
\hline Secondary & 33 & 36.5 \\
\hline Basic & 15 & \\
\hline None & 38 & 37.5 \\
\hline Occupation & & 22.1 \\
\hline Farmer & 39 & 3.8 \\
\hline Trader/Artisan & 23 & 36.5 \\
\hline Government worker & 4 & \\
\hline Others & 38 & \\
\hline
\end{tabular}

Table 2: Malaria Identification

\begin{tabular}{|lrr|}
\hline \multicolumn{1}{|c}{ Malaria identification } & RESPONSE \\
INDICATOR & Yes $\mathrm{n}(\%)$ & No $\mathrm{n}(\%)$ \\
Using history of fever/fever presents & $100(96.2)$ & $4(3.8)$ \\
Urban & $38(95)$ & $2(5)$ \\
Peri-Urban & $25(96.2)$ & $1(3.8)$ \\
Rural & $37(97.4)$ & $1(2.6)$ \\
Prompt identification & $82(78.8)$ & $22(21.2)$ \\
Urban & $29(72.5)$ & $11(27.5)$ \\
Peri-Urban & $22(84.6)$ & $4(15.4)$ \\
Rural & $31(81.6)$ & $7(18.4)$ \\
Using fever as key feature & $96(92.3)$ & $8(7.7)$ \\
Urban & $36(90)$ & $4(10)$ \\
Peri-Urban & $24(92.3)$ & $2(7.7)$ \\
Rural & $36(94.7)$ & $2(5.3)$ \\
Awareness of danger signs by CBAs & $92(88.5)$ & $88.5(12)$ \\
Urban & $39(97.5)$ & $1(2.5)$ \\
Peri-Urban & $20(76.9)$ & $6(23.1)$ \\
Rural & $33(86.8)$ & $5(13.2)$ \\
Correct description of danger signs by CBAs & $47(44.2)$ & $57(55.8)$ \\
Urban & $20(50)$ & $20(50)$ \\
Peri-Urban & $12(46.2)$ & $14(53.8)$ \\
Rural & $15(39.5)$ & $23(60.5)$ \\
\hline
\end{tabular}


two trained community based agents, but only one agent is resourced to provide presumptive treatment of malaria.

\section{Study population:}

The study was conducted among CBAs who were trained to assess and treat children with malaria presumptively. Excluded from them were: all CBAs who were trained but did not possess the treatment tool kit and other community based surveillance workers (CBSV) who are not trained under the HMM strategy to provide treatment.

\section{Study Duration:}

The study took place from October to December 2013.

\section{Sampling and Sample size:}

From a total 197 communities, 100 were randomly selected involving 104 CBAs in four sub districts. The number of CBAs per sub district was determined using probability proportional to size sampling method. The local health sector of each sub district in the Metropolis is divided into zones. From each sub districts, zones were randomly selected, and from selected zones villages were selected using systematic sampling random method. The CBA responsible for providing malaria treatment in the selected communities were contacted.

\section{Data collection and Processing:}

Data were collected through structured interview guide developed by the research team; the interview guide was pre-tested and validated in two sub district of the Sagnarigu district before used in the real data collection. It was self-administered questionnaire while illiterate CBAs were assisted through trained data collectors.

\section{Results}

The study was conducted among 104 participants, $40(38 \%)$ represented urban setting, 26 $(25 \%)$ peri-urban and $38(37 \%)$ rural. The mean age of CBAs was 35.9 years $(S D=8.9)$. Majority $42(40.4 \%)$ of the respondents were within the ages of $30-39$ years. $73.1 \%$ were females and $98 \%$ were married. Only $17.3 \%$ had tertiary education while $31.7 \%$ had secondary education and $37.5 \%$ were farmers. Table (1) summarizes the characteristics of the study participants.

Malaria identification using history of fever was found to be more than $90 \%$ among the respondents across all the three location, similarly, more than $90 \%$ recognized fever as the key indicator in identifying malaria. Furthermore $78.8 \%$ of the respondents identified malaria promptly; however there was a variation in terms of location ranging from $72.5 \%(29)$ among the urban respondents, $84.6 \%$ (22) and $81.6 \%$ (31) among peri-urban and rural respondents respectively. Recognizing danger signs was found to be $88.5 \%$ (92) but the knowledge gap varied from $97.5 \%$ (39) among urban respondent to $76.9 \%$ (20) in peri-urban and $86.8 \%$ (33) among rural respondents. However only $44.2 \%$ (47) were able to correctly describe what dangers signs are but the knowledge level decreased from urban to rural respondents with urban representing $50 \%(20)$, peri-urban $46.2 \%(12)$ and rural $39.5 \%$ (15). Table (2) summarizes the specific findings among each category. $86.5 \%$ of all the respondents provided treatment promptly however only $64.4 \%$ (67) were completing the 3 days treatment duration. Nonetheless there was an increasing pattern in completing the duration of treatment from $55 \%$ (22) among urban to $65.4 \%$ (17) in peri-urban and $73.3 \%$ (28) among rural respondents. $81 \%$ repeated the dose at the right time after the child vomited the drug and gave the dose at the right time when parents forgot to give the dose. In managing temperature, $63.5 \%$ (66) used paracetamol whereas $62.5 \%$ (65) used turbid sponging. The awareness of side effects of antimalarial drug was low among the respondents $24 \%$ (25), urban $35 \%$ (14), peri-urban $23.1 \%(6)$ and rural $13.2 \%(5) .83 .7 \%(87)$ of the respondents referred children with danger signs to the next level whereas $81.7 \%$ (85) did so for children under 6 months. The specific findings are summarized in Table (3).

Also, 90.4\% (94) of the respondents possessed register but only $80.8 \%$ (84) used them to register their activities; $87.5 \%$ (91) reported their activities but $86.5 \%$ (90) did so monthly. This is summarized in Table 4

Overall, only $26 \%$ (27) respondents were motivated in one way or the other by the available motivational packages. $7.7 \%$ (8) were motivated 
Table 3: Management of malaria by CBAs

\begin{tabular}{|c|c|c|}
\hline Management of Malaria & & \\
\hline INDICATOR & Yes $n(\%)$ & No $n(\%)$ \\
\hline CBA providing prompt treatment & $90(86.5)$ & 14(13.5) \\
\hline Urban & $33(82.5)$ & $7(17.5)$ \\
\hline Peri-Urban & $23(88.5)$ & $3(11.5)$ \\
\hline Rural & $34(89.5)$ & $4(10.5)$ \\
\hline CBA Providing 3 days duration of treatment & $67(64.4)$ & $37(35.6)$ \\
\hline Urban & $22(55)$ & $18(45)$ \\
\hline Peri-Urban & $17(65.4)$ & $9(34.6)$ \\
\hline Rural & $28(73.3)$ & $10(26.7)$ \\
\hline CBA providing 2 doses in a day & $34(32.7)$ & $70(67.3)$ \\
\hline Urban & $17(42.5)$ & $23(57.5)$ \\
\hline Peri-Urban & $8(30.8)$ & $18(69.2)$ \\
\hline Rural & $9(23.7)$ & $29(76.3)$ \\
\hline Correct duration of repeating dose after vomiting & $81(77.9)$ & $23(22.1)$ \\
\hline Urban & $33(82.5)$ & $7(17.5)$ \\
\hline Peri-Urban & $22(84.6)$ & $4(15.4)$ \\
\hline Rural & $26(68.4)$ & 12(31.6) \\
\hline Right time of repeating a dose after forgetting & $81(77.9)$ & $23(22.1)$ \\
\hline Urban & $34(85)$ & $6(15)$ \\
\hline Peri-Urban & $22(84.6)$ & $4(15.4)$ \\
\hline Rural & $25(65.8)$ & $13(34.2)$ \\
\hline Use of paracetamol in fever by CBA & $66(63.5)$ & $38(36.5)$ \\
\hline Urban & $19(47.5)$ & $21(52.5)$ \\
\hline Peri-Urban & 19(73.1) & $7(26.9)$ \\
\hline Rural & $20(73.7)$ & $18(26.3)$ \\
\hline Turbid sponging & $65(62.5)$ & $39(37.5)$ \\
\hline Urban & $27(67.5)$ & $13(32.5)$ \\
\hline Peri-Urban & $14(33.8)$ & $12(66.2)$ \\
\hline Rural & $24(63.2)$ & $14(36.8)$ \\
\hline Awareness of side effects of antimalaria drug by CBA & $25(24)$ & $79(76)$ \\
\hline Urban & $14(35)$ & $26(65)$ \\
\hline Peri-Urban & $6(23.1)$ & $20(76.9)$ \\
\hline Rural & $5(13.2)$ & $33(86.8)$ \\
\hline Referral of child with danger sign & $87(83.7)$ & $17(16.3)$ \\
\hline Urban & $35(87.5)$ & $5(12.5)$ \\
\hline Peri-Urban & $23(88.5)$ & $3(11.5)$ \\
\hline Rural & $29(76.3)$ & $9(23.7)$ \\
\hline Referral of children below 6 months & $85(81.7)$ & $19(18.3)$ \\
\hline Urban & $35(87.5)$ & $5(12.5)$ \\
\hline Peri-Urban & $18(69.2)$ & $8(30.8)$ \\
\hline Rural & $32(84.3)$ & $6(15.7)$ \\
\hline
\end{tabular}


by retention of $50 \%$ sales on the drugs, $46.2 \%$ (48) by their involvement in other activities such as NIDs but with a downward trend in term of location ranging from $47.5 \%$ (19) among urban respondents to $46.2 \%$ (12) and $44.7 \%$ (17) among the peri-urban and rural respondents respectively. The provision of T-shirts and other paraphernalia motivated $11.5 \%$ (12) whereas the provision of bicycles motivated $18.3 \%$ (19). Majority $47.1 \%$ (49) were motivated by the respect and recognition given offered them by community members. Respect and recognition as a form of motivation was high $65.8 \%$ among rural respondent compared to $53.8 \%$ (14) among peri-urban and $25 \%$ (10) among urban respondents respectively

\section{Discussion}

Malaria identification is key in order for the necessary actions needed to be taken to prevent its complication. Early identification at home or in the community is a major component of the CBAs responsibility [6] and it is particularly important for early initiation of treatment. The findings of this study demonstrated a remarkable ability of CBAs to identify malaria early using fever as well as the danger signs associated, but with little variation across the three locations within the Metropolis. The common danger signs identified by CBAs were inability of children to feed (eat or drink), severe vomiting, convulsion, and unconsciousness. The ability of respondents to correctly describe danger signs to mean warning signs indicating, a sick child may be suffering from a serious health condition and therefore need immediate attention as described by the c-IMCl Participants Training Manual (2010) [8] was poor; a slight variation existed between urban, peri-urban and rural locations respectively.

\section{Management of malaria by CBAs}

The findings of this study shows that majority of the CBAs were providing presumptive treatment of malaria among children under five years promptly. The patronage of rural CBAs services were higher among rural CBAs than peri-urban and urban CBAs respectively. This indicates that the implementation of HMM in urban settings is possible but its impact would be much better in rural settings. The high patronage of CBAs especially services at the peri-urban and rural settings where advance health facilities are lacking is encouraging as their services are cements the gap and could lead to improved malaria case management at the community level and contribute to lessening the severity and mortality due to malaria 9, 10. This study also reveals that although most of the CBAs abide by the three days treatment duration, only a few complied with the correct number of doses per day which was found to be more prevalent among rural CBA. This suggest that adherence to malaria treatment by CBAs remains a challenge and could lead to the development of drug resistant malaria parasites, hence, emphasizing the need for regular refresher training for CBAs and stressing on adherence to treatment during such trainings and during supervisory and monitoring activities. In this study, most of the CBAs were repeating doses of antimalaria drugs at the right time when mothers/care givers forgot or when the drug is vomited by sick children, however, urban and peri-urban CBAs performed better than their rural colleagues. Majority of the CBAs in the urban and peri-urban Tamale were adequately managing temperature cases using paracetamol or turbid sponging but only a few were aware of the side effects of the drugs they administer. On the contrary, less than half of CBAs in the rural Tamale were managing temperature using paracetamol and were neither aware of side effects of antilalaria drugs nor managing these side effects properly according to standard procedure. This could be dangerous as most CBAs may not be able to properly educate their clients on the side effects of antimalaria drugs and how to manage it when it occurs.

\section{Referral of children with danger signs by CBAs}

The findings of this study show that a significant portion of the CBAs knew the conditions for which to refer cases. The referral of children with danger signs was 11 times higher among urban and peri-urban than rural CBAs while the referral of children below six months was 18.2 and 16.1 times higher among urban and rural CBAs than peri-urban CBAs. The rate of case referrals by CBAs was found to be higher compared with other previous studies [11, 12]. However, most of the referrals made did not conform to the correct referral procedure. Most of referrals were observed to be done by persons with higher education, elderly and married, implying that people with such features should be considered for 
Table 4: Recording and reporting

\begin{tabular}{|lrr|}
\hline Recording and Reporting & \multicolumn{2}{c|}{ RESPONSE } \\
Possession of register by CBAs & & No $\mathrm{n}(\%)$ \\
Urban & Yes n(\%) & $10(9.6)$ \\
Peri-Urban & $94(90.4)$ & $2(5)$ \\
Rural & $38(95)$ & $2(7.7)$ \\
Recording of activities by CBAs & $24(92.3)$ & $6(15.8)$ \\
Urban & $32(84.2)$ & $14(13.5)$ \\
Peri-Urban & $90(86.5)$ & $4(10)$ \\
Rural & $36(90)$ & $2(7.7)$ \\
Recording in the log book & $24(92.3)$ & $8(21.1)$ \\
Urban & $30(78.9)$ & $20(19.2)$ \\
Peri-Urban & $84(80.8)$ & $9(22.5)$ \\
Rural & $31(77.5)$ & $3(11.5)$ \\
Reporting by CBAs & $23(88.5)$ & $8(21.1)$ \\
Urban & $30(78.9)$ & $13(12.5)$ \\
Peri-Urban & $91(87.5)$ & $4(10)$ \\
Rural & $36(90)$ & $2(7.7)$ \\
Monthly reporting & $24(92.3)$ & $7(18.4)$ \\
Urban & $31(81.6)$ & $14(13.5)$ \\
Peri-Urban & $90(86.5)$ & $7(17.5)$ \\
Rural & $33(82.5)$ & $2(7.7)$ \\
\hline
\end{tabular}

Table 5: Table Motivation of CBAs

\begin{tabular}{|c|c|c|c|}
\hline \multirow[t]{2}{*}{ Motivation } & \multicolumn{3}{|c|}{ RESPONSE } \\
\hline & Yes $n\left({ }^{\circ}\right.$ & & No $n(\%)$ \\
\hline Retention of $\mathbf{5 0 \%}$ & $8(7.7)$ & $96(92.3)$ & \\
\hline Urban & $3(7.5)$ & $37(92.5)$ & \\
\hline Peri-Urban & $3(11.5)$ & $23(88.5)$ & \\
\hline Rural & $2(5.3)$ & $36(94.7)$ & \\
\hline Involvement in other activities & $48(46.2)$ & $56(53.8)$ & \\
\hline Urban & 19(47.5) & $21(52.5)$ & \\
\hline Peri-Urban & $12(46.2)$ & $14(53.8)$ & \\
\hline Rural & $17(44.7)$ & $21(55.3)$ & \\
\hline Given T-shirts and others & $12(11.5)$ & $92(88.5)$ & \\
\hline Urban & $3(7.5)$ & $37(92.5)$ & \\
\hline Peri-Urban & $3(11.5)$ & $23(88.5)$ & \\
\hline Rural & $6(15.8)$ & $32(84.2)$ & \\
\hline Given bicycle & 19(18.3) & $85(81.7)$ & \\
\hline Urban & $3(7.5)$ & $37(92.5)$ & \\
\hline Peri-Urban & $3(11.5)$ & $23(88.5)$ & \\
\hline Rural & $13(34.2)$ & $25(65.8)$ & \\
\hline Respect and recognition by community members & $49(47.1)$ & $55(52.9)$ & \\
\hline Urban & $10(25)$ & $30(75)$ & \\
\hline Peri-Urban & 14(53.8) & $12(46.2)$ & \\
\hline Rural & $25(65.8)$ & $13(34.2)$ & \\
\hline Total Responses & $27(26)$ & $77(74)$ & \\
\hline
\end{tabular}


selection to be trained as CBAs [14].

\section{Conducting Follow Ups by CBAs}

This study suggest that most of the CBAs conducted follow ups on children under five years who reported with malaria to them. In accordance with their responsibilities, they are expected to perform some specific activities during follow ups, majority of the CBAs performed such duties during such visits; the only activity that was mostly not performed was treatment of new simple conditions.

\section{Recording and Reporting by CBAs}

Documentation and reporting to the higher level is a requirement by CBAs, this is influenced by the availability of registers/log books. The findings of this study put to the fore that most of the CBAs in all the locations had registers but the level of possession declined slightly from urban to rural. A larger proportion used their registers in documenting activities, peri-urban CBAs frequently did so than urban and rural CBAs. Although majority indicated they recorded and reported their activities, only a few $(27.8 \%)$ of these reports were received by the District Focal Person of HMM between January and June 2013. For the purpose of proper records keeping, the ability to read and write is a criteria for selection of CBAs [14], from this study, a little above half of CBAs recorded their own activities especially among urban and peri-urban CBAs compared to their rural colleagues. All CBAs who were not educated depend on others for activity recording, which emphasizes the recommended criteria of selecting CBAs who can read and write to facilitate easy documentation and reporting.

\section{Motivation of CBAs}

The motivation of CBAs to work comes in different forms including the retention of $50 \%$ cost of treatment, involvement in other health activities such as NIDS and SIAs, provision of T-shirts, bicycles etc and the respect and recognition given them by community members. Well motivated CBAs are more likely to provide their best compared with little or none motivated ones. In this and other studies, motivation of CBAs was found to be low $[11,15]$. The involvement of CBAs in other activities such as NIDs is the major motivating factor for urban respondents whereas peri-uban and rural respondents are motivated by the respect and recognition offered them by community members $[14,16]$. This is particularly so because the amount earn during such activities as NIDs and SIAs are usually quite substantial. The idea of volunteerism by CBAs cannot be sustained without efficient incentive or motivational package for them and therefore suggests the integration of CBAs into other health and development programs as a form of motivation to ensure sustainability [17]. The involvement of community members in the selection and management of the CBAs and their activities is crucial for its sustainability. There is an anxious growing concern by CBAs for remuneration in the form of salary or monthly stipend

\section{Conclusion:}

CBAs are performing well in the identification and management of malaria at the community level but their knowledge on the side effects of antimalarial drugs is poor.There is no significant difference in the performance and ability of CBs to manage malaria in children less than five years in urban, peri-urban and rural Tamale. Documentation and reporting as well as motivation of CBAs remain a challenge. If community interventions such as community drug distribution of antimalarial drugs are needed to improving access to malaria prevention, much attention to what motivates individuals to strengthen their spirit of volunteerism is required.

\section{Conflict of interest:}

Authors disclose that there are no financial or other relevant competing interests.

\section{Acknowledgement:}

Authors would like to acknowledge the support received from all colleagues, particularly Yahaya Abdul Jabar, Wilfred Agongo, Abu Isahaku for the support in data collection; Abdul-Rahman Abdulai for his support in some data entry; and Abdul Karim Mohammad for secretariat support.

\section{Abbreviations}

CBAs: Community Based Agents; CDDs: Community Drug Distributors; WHO: World Health Organization; HMM: Home Base Management of Malaria; KNUST: Kwame Nkrumah University of Science and Technology CHREP: Committee 
on Human Research, Publications and Ethics; C-IMCl: Community Integrated Management of Childhood Illness

\section{Reference}

1. www.who.int/malaria/publications/world-malariareport.../wmr2015-keypoints_eng.p

2. Zlotkin S, Newton S, Aimone AM, et al. (2013) Effect of iron fortification on malaria incidence in infants and young children in Ghana: a randomized trial. JAMA 310: 938-947.

3. Hunt RH, Fuseini G, Knowles S, et al. (2011) Insecticide resistance in malaria vector mosquitoes at four localities in Ghana, West Africa. Parasites \& vectors 4: 1 .

4. Owusu-Agyei S, Asante KP, Adjuik M, et al. (2009) Epidemiology of malaria in the forest-savanna transitional zone of Ghana. Malaria Journal 8: 1.

5. Dodoo AN, Fogg C, Asiimwe A, et al. (2009) Pattern of drug utilization for treatment of uncomplicated malaria in urban Ghana following national treatment policy change to artemisinincombination therapy. Malaria journal 8: 1.

6. Organization WH (2004) World malaria report 2004: World Health Organization.

7. Pagnoni $F$ (2009) Malaria treatment: no place like home. Trends in parasitology 25: 115-119.

8. Ghana Health Service (2010): Community Integrated management of Chilhood IIness

9. Das LK1, Jambulingam P, Sadanandane C. Impact of community-based presumptive chloroquine treatment of fever cases on malaria morbidity and mortality in a tribal area in Orissa State, India. Malar J. 2008 May 5;7:75. doi: 10.1186/14752875-7-75.

10. Joan N. Kalyango,* Ann Lindstrand, Elizeus Rutebemberwa, Sarah Ssali, Daniel Kadobera, Charles Karamagi, Stefan Peterson, and Tobias Alfven Increased Use of Community Medicine Distributors and Rational Use of Drugs in Children Less than Five Years of Age in Uganda Caused by Integrated Community Case Management of Fever. Am J Trop Med Hyg. 2012 Nov 7; 87(5 Suppl): 36-45. doi: 10.4269/ajtmh.2012.11-0733 PMCID: PMC3748520

11. Karin Källander, Göran Tomson, Jesca NsungwaSabiiti, Yahaya Senyonjo, George Pariyo, and Stefan Peterson (2006). Community referral in home management of malaria in western Uganda: A case series study BMC International Health and Human Rights 2006, 6:2
12. Oryema-Lalobo M. Community health seeking practices for the management of malaria of the under-five in Bugiri District, Uganda. East Afr J Public Health. 2009 Aug;6(2):191-6

13. Organization WH (2004) World malaria report 2004

14. Peter Agyei-Baffour, Kristian S Hansen, Edmund N L Browne, and Pascal Magnussen (2012). The amount and value of work time of community medicine distributors in community case management of malaria among children under five years in the Ejisu-Juaben District of Ghana Malaria Journal 2012,11:277

15. Anthony Begumisa, Samson Kironde, Xavier Nsabagasani, Elizabeth Ekochu, Harriet Nassamula2 (2007). Action Research on Improving Motivation of Community Medicine Distributors, (CMDs) and other Community-based Health Workers

16. Katabarwa M. N., Habomugisha P., Richards F. O. Jr and Hopkins D. (2005). Community-directed interventions strategy enhances efficient and effective integration of health care delivery and development activities in rural disadvantaged communities of Uganda. Tropical Medicine and International Health, volume 10 no 4 pp 312-321 April 2005

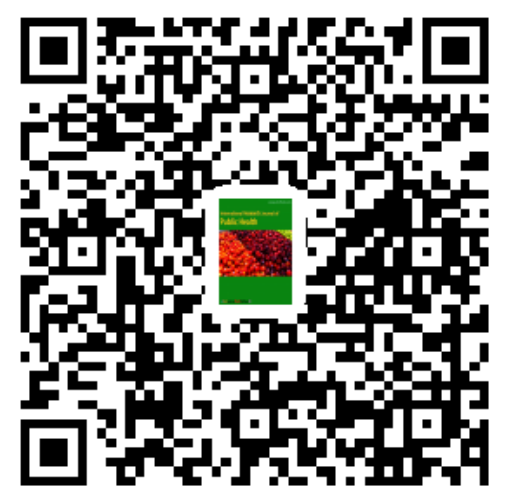


- Title: International Research Journal of Public Health

- ISSN: 2573-380X

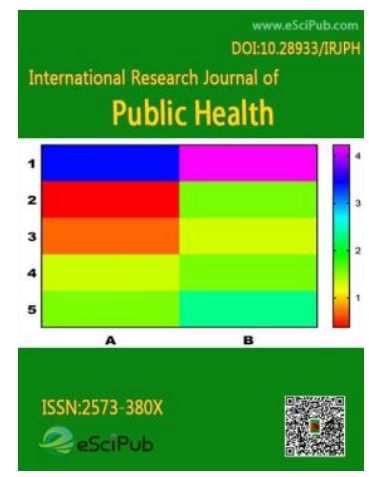

- DOI: $10.28933 / \mathrm{IRJPH}$

- IF: 1.36 (citefactor)

- Email: IRJPH@escipub.com

- TEL: +1-281-656-1158

\title{
About the journal
}

The journal is hosted by eSciPub LLC. Our aim is to provide a platform that encourages publication of the most recent research and reviews for authors from all countries.

\begin{abstract}
About the publisher
eSciPub LLC is a publisher to support Open Access initiative located in Houston, Texas, USA. It is a member of the largest community of professional publishers in the United States: the Independent Book Publishers Association. It hosts more than 100 Open Access journals in Medicine, Business \& Economics, Agriculture, Biological Sciences, Chemistry, Education, Physical Sciences, Sociology, and Engineering and Technology.
\end{abstract}

\section{Rapid Response Team}

Please feel free to contact our rapid response team if you have any questions. Our customer representative will answer your questions shortly.

\section{BY 4.0}

This work and its PDF file(s) are licensed under under a Creative Commons Attribution 4.0 International License.

\section{Terms of Use/Privacy Policy/ Disclaimer/ Other Policies:}

You agree that by using our site, you have read, understood, and agreed to be bound by all of our terms of use/privacy policy/ disclaimer/ other policies (click here for details). This site cannot and does not contain professional advice. The information on this site is provided for general informational and educational purposes only and is not a substitute for professional advice. Accordingly, before taking any actions based upon such information, we encourage you to consult with the appropriate professionals. We do not provide any kind of professional advice. The use or reliance of any information contained on this site or our mobile application is solely at your own risk. Under no circumstance shall we have any liability to you for any loss or damage of any kind incurred as a result of the use of the site or our mobile application or reliance on any information provided on the site and our mobile application. We may publish articles without peer-review. Published articles of authors are open access. Authors hold the copyright and retain publishing rights without restrictions. Authors are solely responsible for their articles published in our journals. Publication of any information in authors' articles does not constitute an endorsement by us. We make no representation or warranty of any kind, express or implied, regarding the accuracy, adequacy, validity, reliability, availability or completeness of any information that authors provided. more..... 